\title{
EFFECTIVE HEARING CONSERVATION DEMANDS NEW TECHNOLOGY AND RE-ENGINEERING
}

\author{
R.J. Steenkamp \\ Department of Business Management \\ Unisa, South Africa \\ steenrj@unisa.ac.za
}

\begin{abstract}
The World Health Organization (WHO) lists noise-induced hearing loss (NIHL) among the most critical global health concerns, given the high NIHL compensation statistics and a figure of up to 10,000 noise-related deaths each year. Industrial engineers / operations managers are now confronted with a serious challenge to control firstlevel noise in a modern engineering context to ensure that machines are quiet and administrative controls are well maintained. While noise continues, however, second-level noise control (hearing conservation) needs to be effective. To this end, a new management approach, re-engineering, redesign, and new hearing conservation programme (HCP) technology are required. The focus of this report is on an HCP model based on new HCP technologies (and management approaches) and a quality management method referred to as 'verification methodology'.
\end{abstract}

\section{OPSOMMING}

Die wêreldgesondheidorganisasie (WHO) lys NIHL (geraasdoofheid) onder die mees kritieke globale gesondheidsprioriteite, gegewe die hoë NIHL kompensasiestatistiek en die ongeveer 10,000 geraasverwante sterftes per jaar. Bedryfsingenieurs en operasionele bestuurders word nou gekonfronteer met hierdie ernstige uitdaging wat beteken dat eerste vlak geraasbeheer in die konteks van moderne ingenieurswese gedoen moet word sodat masjiene gestil word en administratiewe beheermaatreëls goed in stand gehou word. Terwyl geraas voortduur, moet tweede vlak geraasbeheer (gehoorkonservering) effektief wees, wat ' $n$ nuwe bestuursbenadering, heringenieuring ("re-engineering"), herontwerp, en nuwe gehoorkonserveringsprogramtegnologie vereis. Die fokus van hierdie artikel is op ' $n$ gehoorkonserveringsmodel gebaseer op nuwe gehoorkonserveringstegnologie (en bestuurs-benaderings) en ' $n$ gehaltebestuur-metode wat as ' $n$ verifikasiemetodologie verwys word. 


\section{INTRODUCTION}

Professional empowered management of hearing conservation programmes (HCPs) is the only way to address noise-induced hearing loss (NIHL) effectively, because hearing loss is so common that it is considered a normal, inevitable fact of life. The problem is made more complex by different types of hearing loss such as acoustic trauma, otitic blast injuries, conductive hearing loss, sensorineural hearing loss, presbycusis, and others. Though preventable, NIHL is irreversible, and the high level of compensation payouts is shocking evidence of the extent of this condition.

Prolonged exposure to noise can cause incapacitating ill effects - for instance, by making inroads on performance, safe behaviour, attentiveness, problem-solving, and memory. The multidimensionality of the problem calls for a holistic management approach to hearing conservation. In practice noise control is a complex problem for instance, it is understandably difficult to manage a hearing conservation programme (HCP) with limited knowledge and resources. The following regulation emphasises this challenge.

Section 8 of the Occupational Health and Safety Act (No. 85 of 1993) requires medical surveillance, which (among other things) includes recording a baseline audiogram (BA). Besides the practical difficulties of a BA, several other questions are raised. Health and Safety $(H \& S)$ practitioners also need to operate in compliance with the Occupational Health and Safety Act, the Environmental Regulations for Workplaces (section 7), the Mines Health and Safety Act, the NIHL Regulations 2003, COID Circular Instruction 171, SANS 10083:2004 (which defines baselines, audiometers and other guidelines), and the Compensation for Occupational Injuries and Diseases Act, 1993. They also face the consequences of NIHL (audiological, financial and psychological), equipment and calibration for audiometric testing, and the quality of audiometric testing, to mention a few.

\section{LIMITATIONS OF HCPS}

The following limitations of HCPs may be observed:

- $\quad$ HCPs are too fragmented. Another axiom for hearing-loss prevention has been that successful hearing conservation programmes should result when management makes an effort to integrate hearing health information into the overall health and safety climate and culture of the workplace. According to the National Occupational Exposure Survey (conducted by $\mathrm{NIOSH}$ ), companies with an HCP manage it in a fragmented way. Typical tendencies are that more companies provide HP (most of them via inadequate HPDs) than those that provide noise monitoring, and more companies provide noise monitoring than audiometry.

- A personal risk profile and personal coaching are not done. The trend is similar for all businesses - small, medium, and large. The elements of audiometry and hearing protection are also only implemented if the results of monitoring indicate that workers are exposed above the permissible exposure limit (PEL) and no noise control elements have been introduced. 
- No verification of HPDs. There is a widespread belief that hearing conservation programmes can be as effective in preventing hearing loss as noise engineering control programmes that reduce noise to less harmful levels. This implies that noise control capable of reducing the exposure level by $10 \mathrm{~dB}$ will be no more effective than a HPD that reduces the noise exposure level by $10 \mathrm{~dB}$ - and the HPD is certainly less expensive than noise control. The flaw in this assumption is the high variability in the real world performance of HPDs, such as their noise reduction ratings (NRR), which effectively reduced attenuation, as HPDs provide more than $10 \mathrm{~dB}$ of noise reduction for some workers and less for others. Even best-practice HPDs (such as Variphone) that are not applied within a professional HCP can do more harm than good. Vinck [14], Professor in Audiology at Gent University, confirmed that these typical grey areas in hearing 'protection' are caused by a hiatus in legislation, insufficient universal standards (e.g. individual risk profiles based on ISO1999), inadequacies in the knowledge of $H \& S$ practitioners in areas such as different noise levels, risk misconceptions (most countries set the limit between 82 and $85 \mathrm{~dB}$, while some set it as low as $70 \mathrm{~dB}$ ), different exposure periods (PELs), different NRRs, different HPD types (e.g. differences in attenuation properties between acrylic custom and silicon custom HPDs), almost no verification of attenuation (e.g. using an attenuation control unit [ACU]), variable leak-tightness, neglected noise measurement behind the HPD (referred to as 'real ear measurement' [REM]) and/or 'microphone in real ear' [MIRE]). Effective HPDs also promote general quality of work life (QWL), an effect that should be verified. The picture below is an example of process technologies used to seal test custom-fit HPDs and to calibrate HPD filters (right).

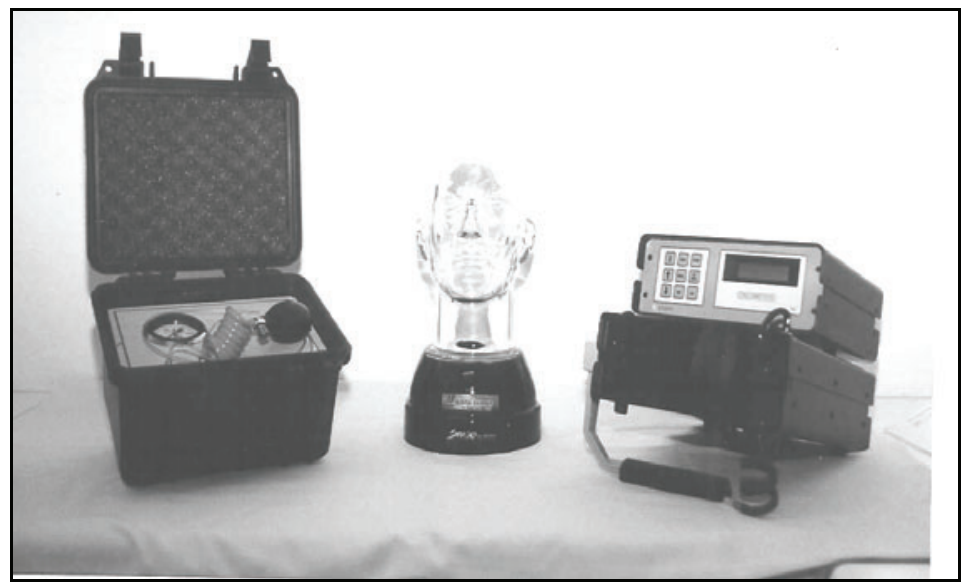

Figure 1: Example of process technologies used to seal test custom-fit HPDs and to calibrate HPD filters 
- $\quad$ There is a lack of personal HCP education and personal HPD training. In general, workers are not well-educated in hearing conservation, nor are they well-trained in hearing protection. Disappointing post-training results have prompted researchers to conduct considerable research into more effective ways, such as behaviour-based safety [2], of communicating with and motivating workers and managers to protect hearing.

\section{PROBLEM INVESTIGATED}

The research problem can be defined in terms of the following three dimensions:

- $\quad$ First, Sections 1 and 2 above describe the broad need for excellence in hearing conservation in terms of regulation and HCP standard(s) to address $\mathrm{NIHL}$.

- $\quad$ Second, Section 2 above sets out the problem of the limitations of current HCP designs.

- Third, solutions are investigated in terms of new developments, new technology, and new management approaches to form an HCP model framework (a new ISO standard) for effective hearing conservation.

\section{OBJ ECTIVES OF THE ARTICLE}

The main aim is to address the research problem (as defined in Section 3) in terms of a description of HCP developments (in technology) that introduces a paradigm for $\mathrm{HCP}$ excellence. Another objective is to provide an HCP model framework that can be used as a benchmark or foundation for the development of a new HCP ISO standard for the benefit of safety engineers, operations managers, and audiologists in the discipline of occupational health and safety. Finally, the report provides core management principles to assist in the implementation of the HCP, including application of a powerful methodology to verify each HCP component.

\section{RESEARCH METHODS}

The problem statement (Section 2) was addressed by resorting to a research methodology that used the following measuring instruments in the survey:

- A combination of benchmarks (e.g. the Hearing Coach HCP, [7],[8]), case studies, personal qualitative observation, interviews, and secondary research data in search of fundamental efficacy dimensions for an HCP model framework.

- $\quad$ The research sources indicated in Table 1 (Section 6).

\section{RESULTS}

Efficacy criteria and matching technologies for HCPs were identified and consolidated in a suggested model framework for a new ISO standard. Each of the dimensions should be: 
- $\quad$ verified/measured by hearing conservation management (safety engineers/ SHE managers) and implied technology.

One way to do this is to subject each dimension to the quality management methodology, namely 'DMAIC' (see Section 7.2), to obtain a 'zero defect' or 'Six Sigma quality level'. The HCP dimensions and their research sources are summarized in Table 1.

\begin{tabular}{lll}
\multicolumn{1}{c}{ HCP element } & \multicolumn{1}{c}{ Research source } \\
1. $\begin{array}{l}\text { Personal risk profiles for coaching - use } \\
\text { personal dosimeters, OAEs, audiometry, } \\
\text { and the measurement and monitoring of }\end{array}$ & $\begin{array}{l}\text { Secondary sources, qualitative } \\
\text { observation, and recent } \\
\text { empirical research reports }\end{array}$ \\
2. $\quad \begin{array}{l}\text { Personal hearing conservation education } \\
\text { and personal hearing protector training } \\
\text { and assessment }\end{array}$ & $\begin{array}{l}\text { Secondary sources and } \\
\text { qualitative observation }\end{array}$ \\
3. $\begin{array}{l}\text { Verification of personal HPDs in terms of } \\
\text { attenuation, seal, comfort, and } \\
\text { maintenance }\end{array}$ & $\begin{array}{l}\text { Secondary sources and } \\
\text { qualitative observation }\end{array}$ \\
$\begin{array}{l}\text { Verification of personal HPDs to optimise } \\
\text { communication and speech discrimination, } \\
\text { and minimise overprotection } \\
\text { Verification of the application, ownership, }\end{array}$ & Secondary sources \\
wearability, and occupational benefits of \\
HPDs
\end{tabular}

\section{Table 1: Fundamental elements of a hearing conservation program model (ISO standard)}

The HCP elements are described and explained in the next section.

\subsection{Personal risk profiles for coaching}

A personal and customised approach to hearing conservation is crucial, since the variation in individual workers' hearing status, needs and risk environment is limitless. The point of departure is a personal risk profile based on the ISO 1999 standard. Employees should be coached, equipped and monitored according to this risk profile. One element in this is a personal dosimeter (or dosebadge) that can be used by the worker to monitor sound exposure for the full shift or any specified portion of the shift. SANS 10083 provides useful guidelines, but management must make HP more personal. With reference to Section 1.3, the risk profile should convey a clear picture of each employee.

Another new development is the OAE gram. Vinck (in [7]) is an authority on the OAE (otoacoustic emissions) gram, which provides accurate information on the actual condition of the outer hair cells, rated under the rubric of hair cell integrity, for the early detection of damage to the sensory mechanism of the ear. This damage cannot 
be seen by any imaging or scanning system [10]. OAEs provide the only direct way of observing changes in the performance of the ear's sensory mechanism. Any change in the condition of the cochlea can be detected as a change in OAE. This method is important since it detects a pattern not noticed in the standard audiogram. This element of hearing conservation is extremely demanding and requires sufficient resources and know-how. Harmony Gold will use OAEs in 2008 as part of their new $\mathrm{HCP}$. The OAE quantifies damage to the outer hair cells as a percentage (not in $\mathrm{dB}$ ), which is ideal for understanding and personal coaching in a professional HCP. Each human has different natural protection abilities. Some recover quickly after a temporary threshold shift (TTS, while others do not. Some think they get used to noise, although their recovery capacity may decrease. Moderate noise induces the expression of antioxydative enzymes, which play a protective role against otoneurotoxicity (Ehrenberger in [7]).

An attempt to use OAE methods for screening early hearing impairment and objective prediction of pure-tone thresholds in normal and hearing-impaired ears, monitoring noise susceptibility, and determining of disability in cases of $\mathrm{NIHL}$, is important. All the tasks of the audiologist within the HCP are part of this efficacy dimension, although another focus should be on pseudohypacusis as a symptom of the NIHL culture. Large numbers of mine workers incur NIHL, and the financial implications (including compensation) are significant; but the situation is often compounded when they exaggerate their hearing loss (pseudohypacusis) to establish grounds to be awarded compensation payments. Exaggerated hearing loss can be detected with current methods, but the extent of exaggeration cannot be quantified. In an attempt to combat this problem, De Koker [3] investigated ASSR (auditory steady state responses) as a means of estimating pure-tone thresholds, since ASSRs need no response from the patient. De Koker recently published a doctoral thesis on the clinical value of auditory steady-state responses in the audiological assessment of pseudohypacusic workers with NIHL in the South African mining industry. Franz [5] from the CSIR also addressed the noise hazard in his paper, and provided several fundamental requirements and critical focus areas of a $\mathrm{HCP}$.

\subsection{Personal hearing conservation education and personal hearing protector training and assessment}

HPDs such as the conventional earmuff, the Noise Clipper, the Variphone, or Sonomax will never be quick fixes, since servicing, maintenance, knowledge, skills and attitudes are significant factors. Workers must be both HCP-compliant in terms of education and compliant in terms of HPD training. This is a core efficacy dimension because even good products can be misused. HPDs should therefore also be measured in terms of how good users feel about and know the HPD. This competence should be scientifically assessed or examined. Noise Clipper (Pty) Ltd offers an 'E5 \& T5' two-module course to noise-exposed mine workers. One module addresses HCP education (E5) and the other address HPD training (T5). After assessment a worker is declared HCP 'compliant'. Modern technology is being investigated to present the 'E5 \& T5' course on a mass basis for low-skilled workers.

One typical general example is the size of some conventional HPDs. If workers and even audiologists do not know (or are not informed about) the size of their ear 
canals, how will they be able to select the correct size HPD? Workers also need training if tailor-made HPDs are used. Even if they are personally sized and customfit (inserted correctly or incorrectly with no half measures), thorough training must still be provided.

Providing best practice HPDs without best-practice education and training makes an $\mathrm{HCP}$ only as strong as the weakest link. Large South African platinum mines (known for best practice methodologies) are seriously revisiting education and training (and servicing of HPDs) for their noise-exposed workers. This is a standard observation in the South African mining industry. Education and training elements have always been a part of HCPs. However, the effectiveness of this training as a means of inducing sustainable behaviour changes that reduce or eliminate the incidence of occupational NIHL has varied widely. Unfortunately, follow-up studies indicate that while participants demonstrated a considerable gain in knowledge about noise hazards and hearing loss, they frequently showed minimal or only short-term changes in hearing health behaviours. Disappointing post-training results have prompted researchers to conduct considerable research into more effective ways such as behaviour-based safety [2] - to communicate with and motivate workers and managers to protect hearing.

\subsection{Verfication of personal HPDs}

This dimension of the suggested HCP model refers to verification of PPE. A quality personal hearing protector must be subjected to attenuation control (sound reduction of the filters) and the real performance by a 'microphone in real ear' (MIRE) measurement to determine the noise behind the hearing protector [12]. Second-level noise control (through HPDs) is compromised by the use of second-best HPDs, downgraded to the lower third and fourth levels of noise control. If you need comfort, communication ability, hygiene and cost-effectiveness, then ear plugs can never be simple. These 'simply designed' products are not personalised, but are forced (not sized) into the ear. They are also not seal-tested, and the fit can be compromised. It should be as good as first-level noise control, effectively eliminating noise altogether. These 'simple' conventional earplugs have several inherent design flaws that have led to the bizarre situation where standards have to be developed to compensate for these flaws. 'Derating' can be used as an example: a noise reduction rate (NRR) of 30 (which is still perceived to be the criterion for a high quality HPD) is assumed to provide about $15 \mathrm{~dB}$ of real protection, as NIOSH suggest in their 1998 criteria for a recommended standard as 'a variable derating system'. Even if we do use 'derating', we are simply guessing (the opposite of verification), having no idea how much protection any given worker is actually getting from an HPD. NRR should not be used in this way (and has not been standardised in either New Zealand or Australia). Other examples are the European Union (Guideline EN 458) and the Canadian HPD standard, which call for unacceptable overprotection; too much protection can be as bad as too little.

Despite the above-mentioned limitations of 'simple' HPDs, their surprisingly long life cycle continues. The limitations are many, and they have even earned sobriquets such as 'the throw-away effect' (with an annual cost of $\$ 100$ per user for cheap throw-away types). Standards continue to 'make up' for inherent HPD design flaws: the mass of the earmuff must be given to the user (why, if it is too heavy in the first 
place?), the clamping force must be measured by the user, otherwise it must be replaced after six months (or is it five months?). Another grey area is the requirement that 'reusable earplugs must be replaced at least every three months'. It is clearly impossible to apply second-level noise control with second-best.

The appropriate quality HPD is a personalised PPE. The best HPD for the best second-level noise control will therefore be exactly the opposite of what is described above in the first paragraph of this Section. It will be (1) physically sized for comfort, with consistent (low variability) tailor-made sizing, but also (2) comfortable in terms of measured communication, detection, ventilation, and orientation. (3) It will provide enough attenuation (verified) for the specific working zone (verified), and overprotection will be minimised to optimise communication (speech discrimination) and the detection of machines and warning signals. This HPD will be (4) seal-tested (measured) and fitted either correctly or not at all. This product will have (5) hypoallergenic features (as verified) and be cost-effective (verified) owing to durability and high ownership (verified). The HPD will have a filter mechanism (6) of which the calibration setting is both fiddle- and tamperproof. This ideal HPD will also be measured against (7) the ability to accommodate the hearing impaired.

\subsection{Verification of personal HPDs to optimise communication}

The importance of communication in the workplace does not require any explanation. HPDs with high NRRs can provide too much attenuation, causing a feeling of isolation and underlining other dangers of overprotection. HPDs that provide different NRRs to eliminate overprotection should be able to measure and verify exactly how much attenuation different HPDs offer. Laboratory tests (e.g. at the SABS or the CSIR) can provide an excellent indication through laboratory results (in terms of a test report); but these do not add up to a real-world test report. Hager [6] from Sonomax confirms the need for real-world tests with reference to research by EARLog, indicating a large difference (up to $80 \%$ ) between laboratory and real-world values, when comparing 16 different HPDs. A case in point is the attenuation of HPDs: it is conventionally measured as the difference between the subject's pure-tone hearing threshold with and without hearing protection under free field conditions (loudspeaker) in a sound attenuated room. This 'REAT' method is not objective and has several limitations.

One way to double check this core efficacy dimension (HPDs that optimise speech discrimination) is to confirm controlled sounds from the inside. This is the so-called 'insertion gain method' [18]. The hearing aid business may offer several solutions, such as the 'insertion gain' technology. This insertion gain method can be used to assess the attenuation of hearing protectors with acceptable measurement variability. A slender silicone probe-tube, connected to an outside microphone, is inserted into the ear canal, registering the sound pressure level in front of the tympanic membrane. HPDs will also have to be measured 'from inside the ear' using the insertion gain method. This is part of HPD verification where assumed protection value (APV) is compared with the real protection value (RPV). Certain important warning and communication signals therefore need to be assured and verified through measurement. The picture below is an example of a custom-made HPD (from Belgium) that is designed to verify RPV and REM/ MIRE. 


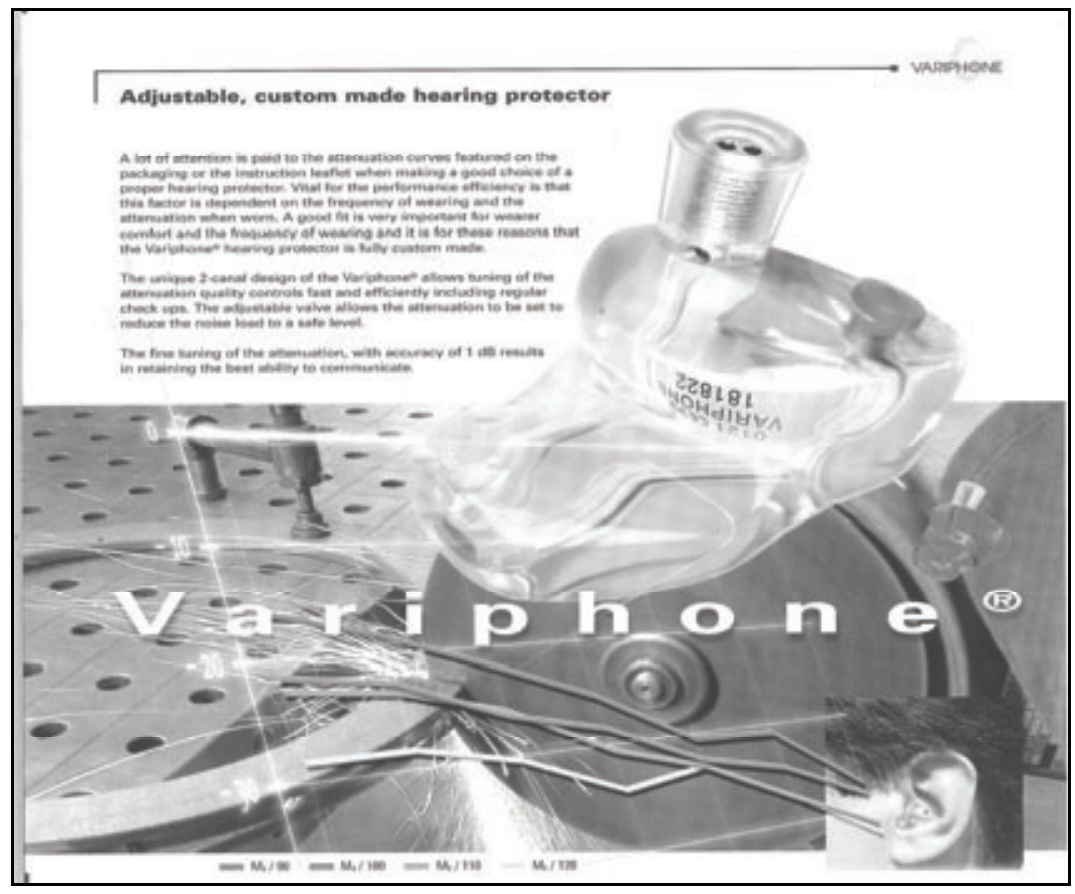

Figure 2: An example of a custom-made HPD (from Belgium) designed to verify RPV and REM/MIRE

\subsection{Verification of the application, ownership, wearability, and occupational benefits of HPDs}

Ownership and wearability must also be verified. Employers usually provide general (vague) positive feedback, reporting that workers wear and maintain their HPDs and do not discard them. If this were true it would be half the battle won; but this dimension needs to be verified/measured. One such study was conducted at a large platinum mine where workers reported on ownership, and indicated that they were satisfied and perceived their otoplastics (custom-made HPDs) to be better than conventional HPDs [9]. This report refers to the perceptions and experiences of platinum mine workers (sample size $n=286$ ) related to this core efficacy dimension.

Workers' attitudes towards the custom-made HPD, and how well it worked for them, are summarised in Table 2 below.

Hearing protection must never cause other dangers. Optimum noise control will result in a situation where workers experience a work environment without harmful noise pollution. This ideal quiet environment is not a world isolated from sound or warning signals. It is a lively world with noise not higher than $85 \mathrm{~dB}$, in which people 
and other resources interact. If a noise hazard necessitates the use of HPDs, then the ideal HPD should provide the worker with optimum protection to provide him/ her with the closest possible approximation of this normal, lively, interactive working environment. HPDs should therefore not make things worse in terms of discomfort, isolation, and so forth - hence the statement that HPDs are not for ears only ('more than meets the ear').

\begin{tabular}{|cccccc} 
& N & Minimum & Maximum & $\begin{array}{c}\text { Mea } \\
n\end{array}$ & $\begin{array}{c}\text { Std } \\
\text { deviation }\end{array}$ \\
$\begin{array}{c}\text { It is better than previous } \\
\text { one }\end{array}$ & 285 & 0 & 3 & 2.49 & .695 \\
$\begin{array}{c}\text { It is comfortable } \\
\text { Good communication on the }\end{array}$ & 286 & 0 & 3 & 2.35 & .723 \\
$\begin{array}{c}\text { job } \\
\text { Hears other sounds better }\end{array}$ & 286 & 0 & 3 & 2.13 & .684 \\
\hline It protects hearing & 281 & 0 & 3 & 2.36 & .593 \\
\hline Likes the colour & 285 & 0 & 3 & 2.65 & .548 \\
\hline Valid N (listwise) & 279 & & & & .623 \\
\hline
\end{tabular}

Table 2: Means and standard deviations of the questions concerning custom-made HPDs

\section{MANAGEMENT OF HCPS, TECHNOLOGY, AND VERIFICATION METHODOLOGIES}

\subsection{Management of HCPs}

Safety leadership implies the following [16]: clear roles, having a champion for the important safety initiative, top management ownership, and constant use of best practices. Weinstein cites the results of a benchmarking study from Petersen in terms of 'best practices in safety performance' as measures that drive continuous improvement, clear performance targets, tying compensation to performance, and consistent application of disciplinary guidelines. $H \& S$ managers must know exactly how effective controls are. They must know what they require (e.g. attenuation) and what they get (real world performance).

HCPs can only be as good as their management. HCPs should be well resourced and managed as a project to get the programme rolled out. Dedicated management (with accountability) should also maintain and sustain the programme by means of three fundamental strategies:

- $\quad$ HCP stations: Besides medical clinic facilities, large industries (e.g. mines) need a separate HCP 'station' to manage and administer hearing conservation. Mines such as Harmony, Lonmin, and Impala are in the process of establishing such stations to do HCP training, HPD fitting, monitoring, and servicing on a full-time basis. 
- $\quad$ Subject each worker to each HCP component (Section 6), which implies verification of hearing conservation.

- $\quad$ Improve the HCP model by means of a continuous cycle of events, such as applying the DMAIC process, and by verifying the HCP model itself (see Section 7.2).

Another axiom for hearing-loss prevention has been that successful hearing conservation programmes should result if management made an effort to integrate the hearing health information into the overall $H \& S$ climate and culture of the workplace. Indeed, data over the years have indicated that workers and managers are more likely to 'buy into' a hearing-loss prevention programme if it has at least equal status with other $H \& S$ initiatives. This appears to be especially important when hearing loss prevention is competing for the workers' attention with other $\mathrm{H} \& S$ initiatives that have the potential to prevent painful injury or fatalities.

\subsection{HCP technology}

HCP technology refers to gadgets, tools, process technologies, modern HPDs (e.g. the various custom-made filter-based systems), measuring instruments (e.g. ACUs), models, and management methodologies. Although not all the technologies discussed may be considered as new, their application, or small changes to instruments, may be new. For instance, the OAE should not replace the conventional audiogram, but complementing it should certainly be considered. This report does not suggest that no other technologies are available, but it does emphasise the desperate need for such new developments, best practices, and optimal use of available technology.

\subsection{Verification methodology}

Large companies that strive for world class performance but have to contend with high costs due to poor quality, use total quality management (TQM), such as Six Sigma methodologies, to achieve breakthroughs. The proposed HCP model (Section 8) can be subjected to a methodology such as Six Sigma because each of the five elements of the HCP must be verified.

Six Sigma (for example) is a popular quality management methodology used by mines such as Lonmin. 'Six Sigma' is an organisation-wide, operationalised, statistically-based continuous improvement approach, incorporated into a projectbased system. Motorola, Johnson \& J ohnson, and General Electric (GE) have gained recognition as users of the methodology. Jack Welch from GE noted that "the initiative started in 1996 delivered $\$ 300$ million to the bottom line in 1997 and $\$ 600$ million in 1998" [1]. It is not linked to any standard or model, but is obsessed with measurement, SPC, continuous learning, and innovation.

- Verification implies measurement to obtain facts for 'moments of truth'. Sigma is a measurement scale according to which improvement on variation can be gauged. Sigma is a measure of 'goodness', using a universal measurement scale. This model has all the components that management 
may need to ensure the total eclipse of noise-induced hearing loss (NIHL). Whatever is included in the HCP, it should be measured and verified. This powerful model is based on DMAIC (define, measure, analyze, improve, control) [1]. Specific tools are used in each of these steps, such as the following:

- $\quad$ DEFINE EACH ELEMENT OF THE HCP - scope boundaries of efficacy dimension or process (e.g. use the first HCP component 'risk profile' a

- $\quad$ MEASURE EACH ELEMENT OF THE HCP - own benchmark values, universal standards, capability, performance facts. (Is the risk profile actually complete? Does it actually provide an accurate picture of workers' risk?)

- $\quad$ ANALYSE EACH ELEMENT OF THE HCP - this is the opposite of systemsthinking, cause-and-effect relationships, tests, variances (analyse the risk profile to make sure it gives a true reflection of all factors contributing to the risk).

- IMPROVE THE ELEMENT OF THE HCP - reduce complexity, apply corrective action, initiate improvement projects (adapt the risk profile to improve it). $s$

- CONTROL THE ELEMENT OF THE HCP - statistical process control charts, audits, determine new capabilities, and share (establish and maintain the improved risk profile).

This process indicates a continuous improvement cycle, and standards such as ISO/TS 16949 can be used to promote continual improvement, prevent defects, and reduce variation and waste in the supply chain. The focus is on core processes that add value to critical-to-quality dimensions for customers [13]. The target should be zero defects, attained with the Six Sigma approach, expecting a defect rate of no more than a few parts per million. Six Sigma reduces variation in the process to a level that - even with a 1.5 standard deviation - leaves the chances of a defect at less than 3.4 parts per million (ppm). A Six Sigma level of 3ppm is 0.999997.

Manufacturers giving thumbsuck figures such as ' $4 \%$ defects per batch' may not realize how high this is $(40,000)$ in terms of ppm. Welldon [17], the group quality manager of Motorola in Australia, says that it is all about achieving sustainable business improvement through integrated team efforts linked to business priorities, such as the elimination of NIHL. Motorola began with Six Sigma in 1986, and achieved several quality awards, such as the Malcolm Baldridge Quality Award in 1988.

\section{INTEGRATION OF THE ELEMENTS OF THE HCP MODEL AND THE VERIFICATION METHODOLOGY INTO AN HCP MODEL}

Figure 3 illustrates the conceptual HCP model by integrating the five HCP elements in a specific sequence and the application of the DMAIC methodology to each HCP element. 


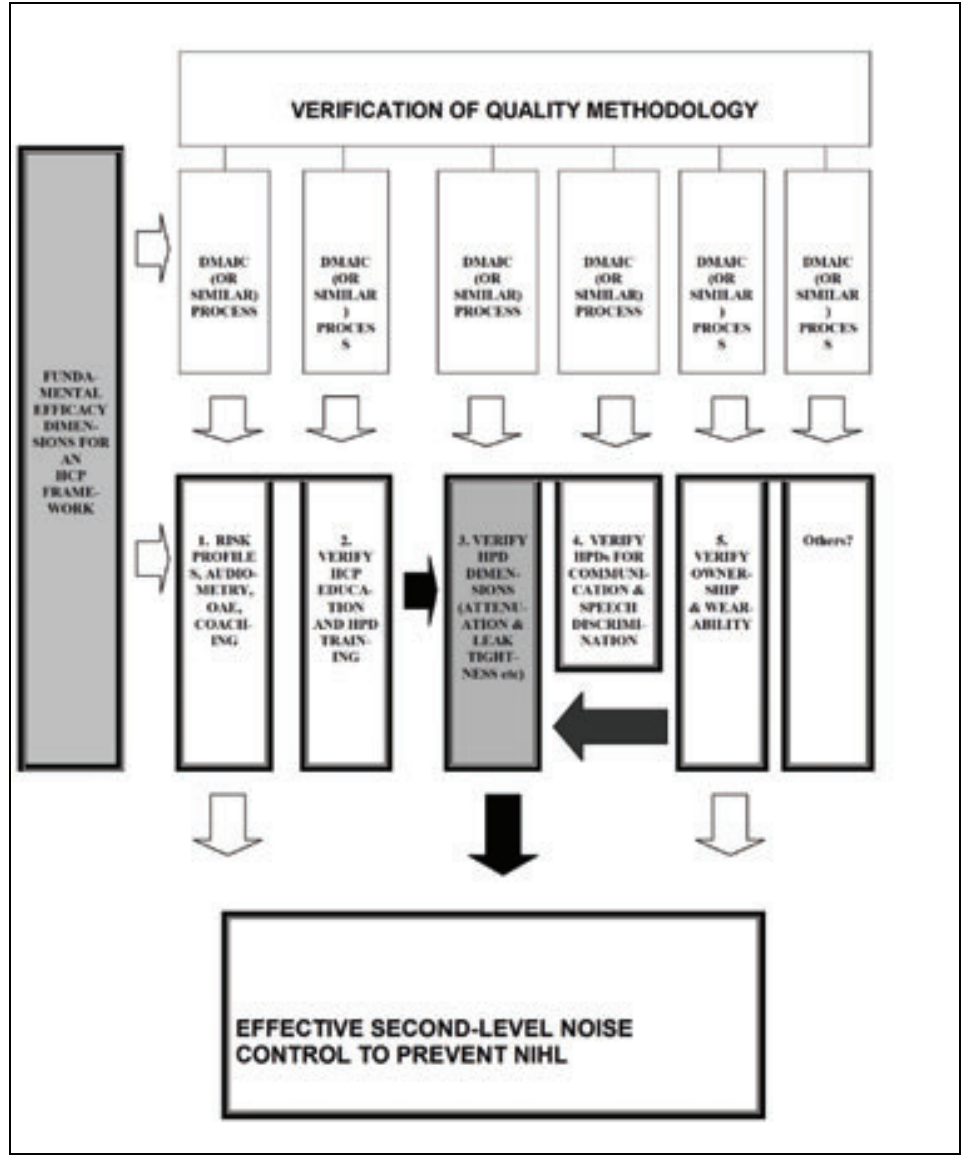

Figure 3: A conceptual model as a basis for an HCP model / ISO standard 


\section{CONCLUSIONS}

The results indicate a TQM (total quality management) or holistic approach to an HCP. The overall result is a model in which the core HCP elements (with appropriate best-practice technology) are combined with a verification methodology (e.g. Six Sigma) to create a best-practice HCP framework. These dimensions can be elaborated upon, refined, and defined differently, but the essence is there. Although the model will also have to be tested (refined, improved, and adjusted), it is clear that an HCP with these five dimensions - and on a Six Sigma level of quality must provide close to zero defect results.

\section{REFERENCES}

[1] Adams, C.W., Gupta, P. \& Wilson, C.E. 2003. Six Sigma deployment. Butterworth Heinemann.

[2] Cooper, D. 2004. Adding value to your company with behavioural safety. Noshcon Conference Proceedings, Sun City, pp 226-230.

[3] De Koker, E. 2004. The clinical value of auditory steady state responses in the audiological assessment of pseudohypacusic workers with NIHL in the South African mining industry. PhD thesis, University of Pretoria, Pretoria.

[4] Diedericks, M. 2005. Personal interview. Lonmin, Marikana.

[5] Franz, R.M. 2002. Addressing the noise hazard: Fundamental requirements and critical focus areas. J ournal of the MVS, J uly/ September.

[6] Hager, L. 2002. Hearing protection: Prevention is the answer. Sonomax. Audiology online.

[7] Hearing Academy Congress, 2005. Proceedings of published papers. Okura Hotel, Amsterdam, Netherlands.

[8] Hearing Academy Congress, 2006. Proceedings of published papers. University of Pretoria, South Africa.

[9] J ournal of Industrial Psychology, 2003. 29 (2), pp 91-97.

[10] Kemp, D.T. 2005. Introduction and explanation of OAEs. Hearing Academy conference, Amsterdam, Netherlands.

[11] Leonard, D. \& McAdam, R. 2004. Total quality management in strategy and operations: Dynamic grounded models. J ournal of Manufacturing Technology Management, 15 (3), pp 254-266.

[12] Lotter, A. 2005. Hearing coach. Ergotec. Belgium.

[13] Oakland, J.S. 2003. TQM: Text with cases. $3^{\text {rd }}$ edition. Butterworth Heinemann. 
[14] Vinck, B. 2006. Hearing academy congress. Proceedings of paper. University of Pretoria, South Africa.

[15] www.NIOSH.com

[16] Weinston, M.B. 1997. Total quality safety management and auditing. Lewis Publishers. New York.

[17] Welldon, B. 2003. Implementing digital six sigma in a Motorola strategic business unit. Paper presented at the VI Congreso Mundial en Management, Santiago, Chile.

[18] Woxen, O. \& Borchgrevink, H.M. 1991. Attenuation of hearing protectors at $85 \mathrm{~dB}$ SPL investigated commercial 'insertion gain' method. Pubmed. National Library of Medicine. 